\title{
A Comparison of the Operational Energy Demand of Both Low Pressure and Vacuum Collection Systems
}

\author{
Philip McCullough, Rodney McDermott \\ Belfast School of Architecture and the Built Environment, Ulster University, Belfast, Northern Ireland \\ Email: mccullough-p6@ulster.ac.uk
}

How to cite this paper: McCullough, $\mathrm{P}$. and McDermott, R. (2020) A Comparison of the Operational Energy Demand of Both Low Pressure and Vacuum Collection Systems. Journal of Water Resource and Protection, 12, 729-740.

https://doi.org/10.4236/jwarp.2020.129044

Received: June 16, 2020

Accepted: September 8, 2020

Published: September 11, 2020

Copyright $\odot 2020$ by author(s) and Scientific Research Publishing Inc. This work is licensed under the Creative Commons Attribution International License (CC BY 4.0).

http://creativecommons.org/licenses/by/4.0/

\begin{abstract}
Climate change is regarded as the greatest threat to society in the coming years, and directly affects the water industry; with changes in temperature, rainfall intensities and sea levels resulting in increased treatment and subsequent energy costs. As one of the largest global consumers of energy, the water industry has the opportunity to significantly prevent climate change by reducing energy usage and subsequent carbon footprints. Wastewater treatment alone requires an estimated $1 \%-3 \%$ of a country overall energy output while producing $1.6 \%$ of its global greenhouse gas emissions; over $75 \%$ of which can be due to the collection system. Gravity flows should therefore be incorporated where possible, reducing pumping requirements and therefore minimizing costs and subsequent carbon footprints. This study has assessed the operational energy usage of the alternative collection systems low pressure and vacuum, for use in situations in which a conventional gravity system is not practicable. This was carried out through hypothetical scenario testing using design parameters derived from literature, generating 60 hypothetical collection mains with variations in population, static head and main length. From this study, it was found that the energy demand of a low pressure system is $3.2-4.2$ times greater than that of its equivalent vacuum system in the same scenario. Energy demand for both systems increases with population, static head and main length. However, population and therefore flow changes were found to have the greatest effect on the energy usage of both systems. Therefore, flow reduction measures should be adopted if the decarbonization of the water industry is to be achieved.
\end{abstract}

\section{Keywords}

Wastewater Collection, Carbon, Energy, Sustainable Development 


\section{Introduction}

The World Commission on Environment and Development (WCED) defines sustainability as "development which meets the needs of the present without compromising the ability of future generations to meet their needs" [1]. Climate change is regarded as the greatest threat to society in the coming years [2], making sustainable development an urgent global priority [3]. The water industry is critical in almost every aspect of society [4], and is directly affected by climate change, with changes in temperature, rainfall intensities and sea levels resulting in increased treatment and subsequence energy costs [5]. Sustainable development is therefore vital for the water industry, as it aims to meet social needs in a changing climate, while conserving resources and protecting the environment at a sustainable price [6].

The water industry is one of the largest global consumers of energy, with wastewater treatment alone requiring an estimated $1 \%-3 \%$ of a countries overall energy output [7], and 1.6\% of global greenhouse gas emissions [8]. The industry is therefore in an important position, with the opportunity to significantly prevent climate change by reducing energy usage and subsequent carbon footprints [9]. A sewerage system can contribute over $75 \%$ of the carbon footprint of a sanitation system [10], therefore gravity flows should be incorporated where possible, reducing pumping requirements and therefore minimizing costs and carbon footprints [11].

The conventional gravity system has been used for thousands of years, therefore all other collection options can be considered to be "alternative" systems [12]. Numerous studies have been carried out on these systems; however the existing literature does not consider the energy demands of the various design options, nor does it evaluate the effects population or elevation changes have on these. This study has sought to help fill this knowledge gap by assessing the operational energy usage of the alternative collection systems low pressure and vacuum. This will help designers evaluate the operational and environmental costs of each option, enabling them to create the smart designs required to minimize pumping costs and subsequent carbon footprints [11].

\section{Background}

The provision of sufficient sanitation is an important requirement for providing a population with a good standard of living [13]. Gravity sewers are the most common form of wastewater collection system [14] and have been found to be an efficient system for areas with a high population density. This system has been used for thousands of years; therefore, all other collection system options can be considered to be "alternative" systems [12] [15]. However, gravity sewers have several limitations, and may not be the most suitable option for certain situations, including where the site topography is flat or the groundwater level is high, leading to infiltration [16].

A vacuum sewer utilizes negative air pressure generated at a centralized va- 
cuum pump to transport wastewater through the network, which is composed of three main components; vacuum valve chambers, vacuum mains and a vacuum station [17]. This collection system was invented by Charles Liernur in 1866 and was installed in towns in Europe including Amsterdam [16], with the first commercial system created by the Lijendahl Corporation (now Electrolux) in 1959 [17]. Vacuum sewer collection systems are considered to be an "eco-innovative" wastewater collection system, preventing the seepages and odors which can occur in a conventional gravity system [18]. These systems have been found to be suitable in different situations including; areas with existing septic tanks; high water tables or nearby watercourses, flat ground topography or difficult ground conditions [19]. Vacuum sewers are limited by their ability to transport wastewater uphill, with the expected capacity to overcome a maximum head of 9.144 m - 12.192 m [20]. However, BS EN 16932; Drain and sewer systems outside buildings-Pumping systems recommend a maximum static head of $5 \mathrm{~m}$. Vacuum collection systems are therefore not viable in locations where the site topography requires wastewater to be transported up large elevations.

Conversely, low pressure sewers have been seen to be an efficient collection system in areas where a conventional low gravity system would not be practicable [21]. A low pressure collection system uses a grinder pump to break up the solids, reducing their size and therefore helping prevent blockage in the pressure sewer. Pipes therefore do not need to maintain a negative gradient and can be constructed at a fixed smaller cover depth, following the land topography and reducing construction costs [22].

Molatore [23] stated that "every sewering option has its place". Significant research has been and is currently being carried out into these systems, with [16] finding that the initial capital costs of conventional gravity sewage systems can be $20 \%$ - $50 \%$ greater than that of alternative systems in difficult areas, including locations with high water tables, flat terrain and unstable or rocky conditions.

Furthermore, the use of onsite wastewater treatment systems (OWTS) was assessed against alternative sewage collection systems by [24], who carried out a cost analysis to determine the best option based on the area's population density. This analysis compared the use of a conventional gravity, vacuum or low pressure grinder pump systems against four OWTS alternatives; namely the use of Conventional OWTS, Landscape Irrigation OWTS, Secondary Biological Units and Advanced Biological units. The results of this analysis concluded that the low pressure grinder sewer is the cheapest collection system for areas of low population density ( $>0.5$ acre average property size), however onsite treatment was considerably cheaper for these options. Conversely, vacuum systems were found to be the most efficient option for medium (0.25 - 0.5 acre) and high $(<0.25$ acre average property size average) density areas. These results are in line with findings from a cost analysis of alternative systems in small communities by [25], which found that the provision of collection systems and WWTWs for small communities was not practicable or economically viable. 
The existing literature however does not consider the energy demands of the various design options, nor does it evaluate the effects population or elevation changes have on these. This study has sought to help fill this knowledge gap by assessing the operational energy usage of the alternative collection systems; low pressure and vacuum. This will help designers evaluate the operational and environmental costs of each option, enabling them to create the smart designs required to minimize pumping costs and subsequent carbon footprints [11].

\section{Methodology}

The purpose of this project was to assess the operational energy requirements, and subsequent carbon footprint, of the alternative low pressure and vacuum collection systems. Molatore [23] stated that "every sewering option has its place", indicating that different systems are better suited to different scenarios. Hypothetical scenario tests were therefore carried out to obtain data for the alternative systems in different situations. This testing method allowed for the creation of accurate data, while assessing several parameters simultaneously [26] [27]. The design parameters were derived from literature, generating 60 hypothetical collection mains with variations in population, static head and main length as seen in Table 1.

Maximum static head was taken as $5 \mathrm{~m}$ in accordance with BS EN 16932; Drain and sewer systems outside buildings-Pumping systems. Airvac Design Manual [28] states that a maximum line length cannot be defined, however recommends that $10,000 \mathrm{ft} \approx 3048 \mathrm{~m}$ be taken as an initial maximum by the designer. The maximum line length for the hypothetical scenario tests was therefore taken as $3000 \mathrm{~m}$. No maximum population was found in literature for either collection system. The maximum population for the hypothetical scenario tests was taken as the largest system found in literature of 10,000 people [15].

The following parameters remained constant for each vacuum system:

- 150 liters per person per day taken in accordance with British Water Flows and Loads Code of Practice and Irish Water Code of Practice for Wastewater Infrastructure [29] [30].

- HDPE pipes were selected in accordance with [31], with industry standard SDR 17 from [32].

- Air/water ratio-taken as a 2:1 volume ratio in accordance with [28].

- Frictional head loss in each system was calculated using the modified Hazen-Williams Formula in accordance with system design manuals [28] [33].

Table 1. Hypothetical scenario design parameters.

\begin{tabular}{cc}
\hline Description & Design Parameter \\
\hline Population (served by collection system) & $100,1000,2500,5000$ and 10,000 \\
Static head $(\mathrm{m})$ & $0,2.5,5$ \\
Main length $(\mathrm{m})$ & $500,1000,2000$ and 3000 \\
\hline
\end{tabular}


- Pipe design coefficient $C$ taken as 150 in accordance with system design manuals [28] [33].

- Vacuum pumps selected from [34], with horizontal centrifugal discharge pumps being selected in accordance with [28].

- Environment One model DH071/DR071 simplex grinder pump stations were used for each low pressure scenario, stated to be the "ideal choice for single-family homes" [35], assuming one pump, and 2.7 people per household in accordance with the Irish Water Code of Practice for Wastewater Infrastructure [30].

- Vacuum collection main pipe diameter was selected based on recommended flowrates from the Airvac design manual [28]. To allow direct comparison between collection systems the low pressure pipe diameter was initially taken as the same as the corresponding vacuum system scenario. Calculations were then repeated with increased pipe diameters to allow an assessment of how the power usage was affected by the pipe size used.

- Daily energy costs were calculated from the SSE Airtricity standard unit rate figure of 19.01 pence per kWh taken from SSE Airtricity statement.

- Daily effective carbon emissions for the UK were calculated from power consumption using the UK Department for Business, Energy \& Industrial Strategy (BEIS) 2019 figures of $0.2556 \mathrm{kgCO}_{2} \mathrm{e}$ per $\mathrm{kWh}$ [36]. These were compared to Ireland's daily effective carbon emissions using an all island average figure of $0.291 \mathrm{kgCO}_{2}$ e per $\mathrm{kWh}$ taken from SSE Airtricity statement.

Using these parameters, derived from literature, 60 hypothetical collection mains were developed as seen in Table 2. A calculation spreadsheet was therefore developed to enable efficient comparisons between systems and scenarios.

Table 2. Hypothetical design scenarios.

\begin{tabular}{|c|c|c|c|c|c|c|c|}
\hline & Pop. & Static head & Distance & & Pop. & Static head & Distance \\
\hline & & $\mathrm{m}$ & $\mathrm{m}$ & & & $\mathrm{m}$ & $\mathrm{m}$ \\
\hline Scenario 1 & 100 & 0 & 500 & Scenario 31 & 2500 & 2.5 & 2000 \\
\hline Scenario 2 & 100 & 0 & 1000 & Scenario 32 & 2500 & 2.5 & 3000 \\
\hline Scenario 3 & 100 & 0 & 2000 & Scenario 33 & 2500 & 5 & 500 \\
\hline Scenario 4 & 100 & 0 & 3000 & Scenario 34 & 2500 & 5 & 1000 \\
\hline Scenario 5 & 100 & 2.5 & 500 & Scenario 35 & 2500 & 5 & 2000 \\
\hline Scenario 6 & 100 & 2.5 & 1000 & Scenario 36 & 2500 & 5 & 3000 \\
\hline Scenario 7 & 100 & 2.5 & 2000 & Scenario 37 & 5000 & 0 & 500 \\
\hline Scenario 8 & 100 & 2.5 & 3000 & Scenario 38 & 5000 & 0 & 1000 \\
\hline Scenario 9 & 100 & 5 & 500 & Scenario 39 & 5000 & 0 & 2000 \\
\hline Scenario 10 & 100 & 5 & 1000 & Scenario 40 & 5000 & 0 & 3000 \\
\hline Scenario 11 & 100 & 5 & 2000 & Scenario 41 & 5000 & 2.5 & 500 \\
\hline Scenario 12 & 100 & 5 & 3000 & Scenario 42 & 5000 & 2.5 & 1000 \\
\hline Scenario 13 & 1000 & 0 & 500 & Scenario 43 & 5000 & 2.5 & 2000 \\
\hline
\end{tabular}




\begin{tabular}{|c|c|c|c|c|c|c|c|}
\hline \multicolumn{8}{|l|}{ Continued } \\
\hline Scenario 14 & 1000 & 0 & 1000 & Scenario 44 & 5000 & 2.5 & 3000 \\
\hline Scenario 15 & 1000 & 0 & 2000 & Scenario 45 & 5000 & 5 & 500 \\
\hline Scenario 16 & 1000 & 0 & 3000 & Scenario 46 & 5000 & 5 & 1000 \\
\hline Scenario 17 & 1000 & 2.5 & 500 & Scenario 47 & 5000 & 5 & 2000 \\
\hline Scenario 18 & 1000 & 2.5 & 1000 & Scenario 48 & 5000 & 5 & 3000 \\
\hline Scenario 19 & 1000 & 2.5 & 2000 & Scenario 49 & 10,000 & 0 & 500 \\
\hline Scenario 20 & 1000 & 2.5 & 3000 & Scenario 50 & 10,000 & 0 & 1000 \\
\hline Scenario 21 & 1000 & 5 & 500 & Scenario 51 & 10,000 & 0 & 2000 \\
\hline Scenario 22 & 1000 & 5 & 1000 & Scenario 52 & 10,000 & 0 & 3000 \\
\hline Scenario 23 & 1000 & 5 & 2000 & Scenario 53 & 10,000 & 2.5 & 500 \\
\hline Scenario 24 & 1000 & 5 & 3000 & Scenario 54 & 10,000 & 2.5 & 1000 \\
\hline Scenario 25 & 2500 & 0 & 500 & Scenario 55 & 10,000 & 2.5 & 2000 \\
\hline Scenario 26 & 2500 & 0 & 1000 & Scenario 56 & 10,000 & 2.5 & 3000 \\
\hline Scenario 27 & 2500 & 0 & 2000 & Scenario 57 & 10,000 & 5 & 500 \\
\hline Scenario 28 & 2500 & 0 & 3000 & Scenario 58 & 10,000 & 5 & 1000 \\
\hline Scenario 29 & 2500 & 2.5 & 500 & Scenario 59 & 10,000 & 5 & 2000 \\
\hline Scenario 30 & 2500 & 2.5 & 1000 & Scenario 60 & 10,000 & 5 & 3000 \\
\hline
\end{tabular}

\section{Results and Discussion}

\subsection{Effect of Collection Main Diameter Change}

Power usage results for a low pressure collection system using two different collection main diameters, operating in the 60 hypothetical scenarios described above can be seen in Figure 1. It can be seen that the design with the smaller diameter mains required more energy in all 60 scenarios, requiring $1.01-4.55$ times the amount of energy compared to their larger diameter alternative. This equates to an energy saving of $0.03-129.9 \mathrm{kWh}$ per day, resulting in the prevention of up to $12,188.89 \mathrm{kgCO}_{2} \mathrm{e}$ emissions per year. It can also be seen from Figure 1 that the energy demand difference from collection main diameter changes in each scenario increases with collection main length. This is due to the difference in frictional head loss per meter between pipe sizes.

Due to the difference in energy demand seen in Figure 1 it can be seen that a low pressure system may require a greater diameter collection main than a vacuum system operating in the same scenario. All further analysis below will therefore use results from the increased diameter low pressure systems, with reference to the original diameter results for comparison. Further work is required to find the optimum pipe sizes for low pressure systems serving different population sizes.

\subsection{Effect of the Energy Industry}

The water industry is one of the largest global consumers of energy, with wastewater treatment alone requiring an estimated $1 \%-3 \%$ of a countries overall 


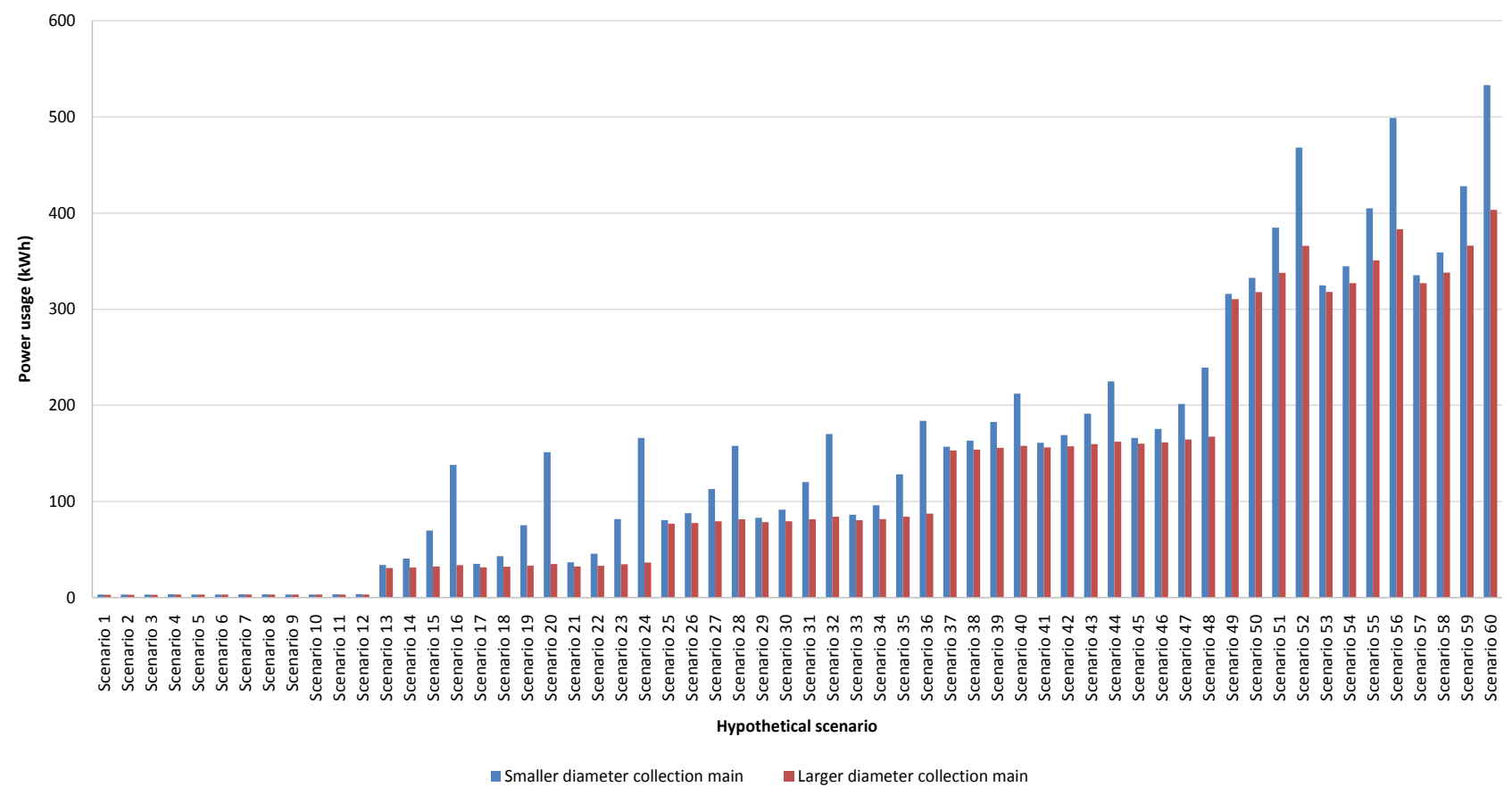

Figure 1. Effects of collection main diameter change on the daily energy demand of a low pressure collection system.

energy output [7], and $1.6 \%$ of global greenhouse gas emissions [8]. The industry is therefore in an important position, with the opportunity to significantly prevent climate change by reducing energy usage and subsequent carbon footprints [9].

A comparison of the effective carbon emissions for the hypothetical scenario testing of a low pressure system with an increased diameter collection main can be seen in Figure 2. Daily effective carbon emissions for the UK were calculated from power consumption using the UK Department for Business, Energy \& Industrial Strategy (BEIS) 2019 figures of $0.2556 \mathrm{kgCO}_{2} \mathrm{e}$ per $\mathrm{kWh}$ [36]. These were compared to Ireland's daily effective carbon emissions using an all island average figure of $0.291 \mathrm{kgCO}_{2} \mathrm{e}$ per $\mathrm{kWh}$ taken from an SSE Airtricity statement. The importance of the energy industry on the emissions of a collection system is highlighted by the variation in results between energy supplies, with a difference of $0.0354 \mathrm{kgCO}_{2}$ e per $\mathrm{kWh}$ equating to a difference of up to $18.88 \mathrm{kgCO}_{2} \mathrm{e}$ per day between suppliers. This confirms the statement from the Committee on Climate change [37] that it will be difficult for the water industry to achieve net-zero emissions without the decarbonization of the energy industry.

\subsection{Comparison of Alternative Collection Systems}

The results of the hypothetical scenario tests of the low pressure and vacuum collecting systems can be seen in Figure 3. There is no vacuum collection system solution for scenario 60 as it is out of the operational range of the largest available Busch Mink MM vacuum pump. This confirms that the parameters selected for the hypothetical scenario testing have covered the entire operational range 


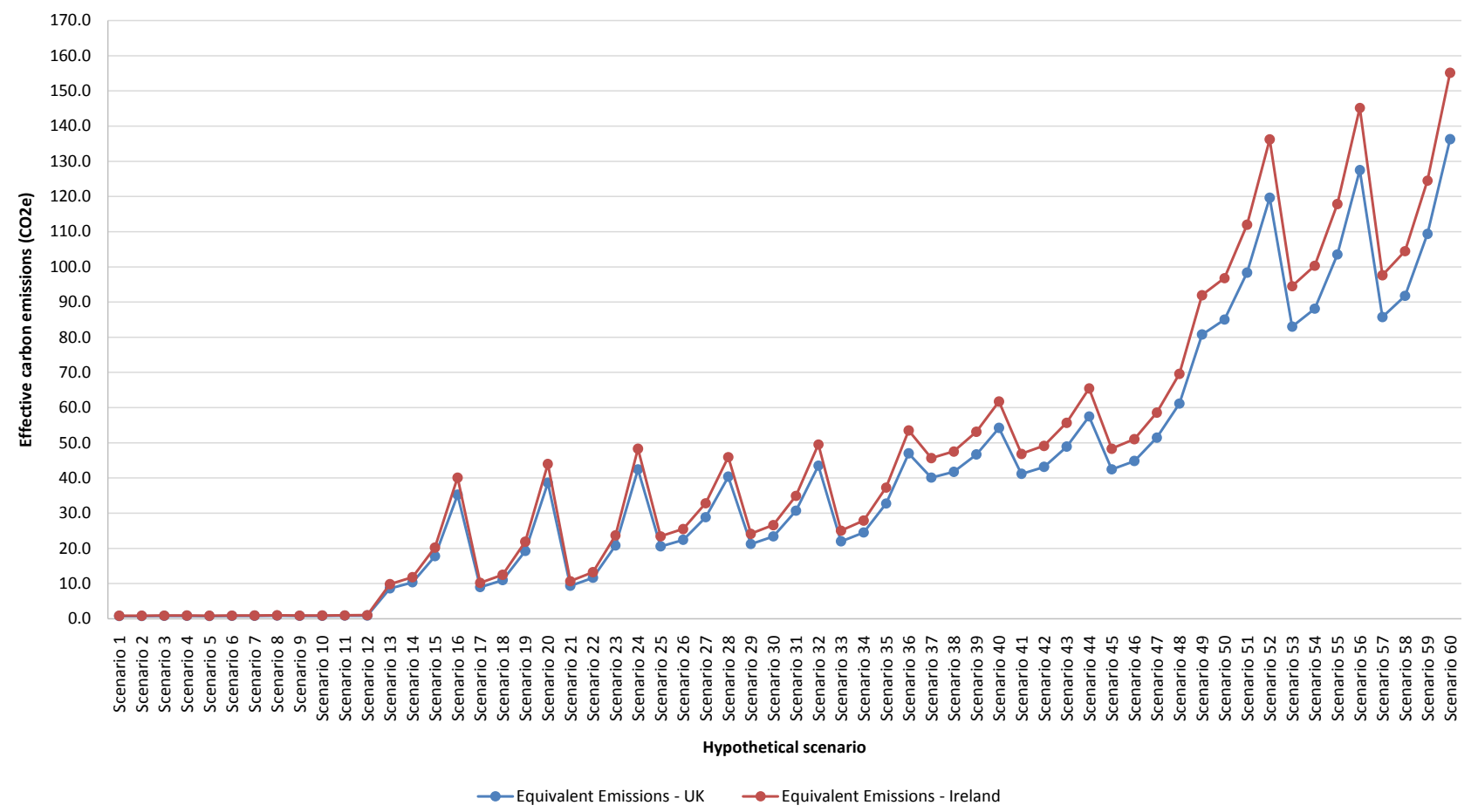

Figure 2. UK and Ireland carbon emissions comparison from the low pressure collection system.

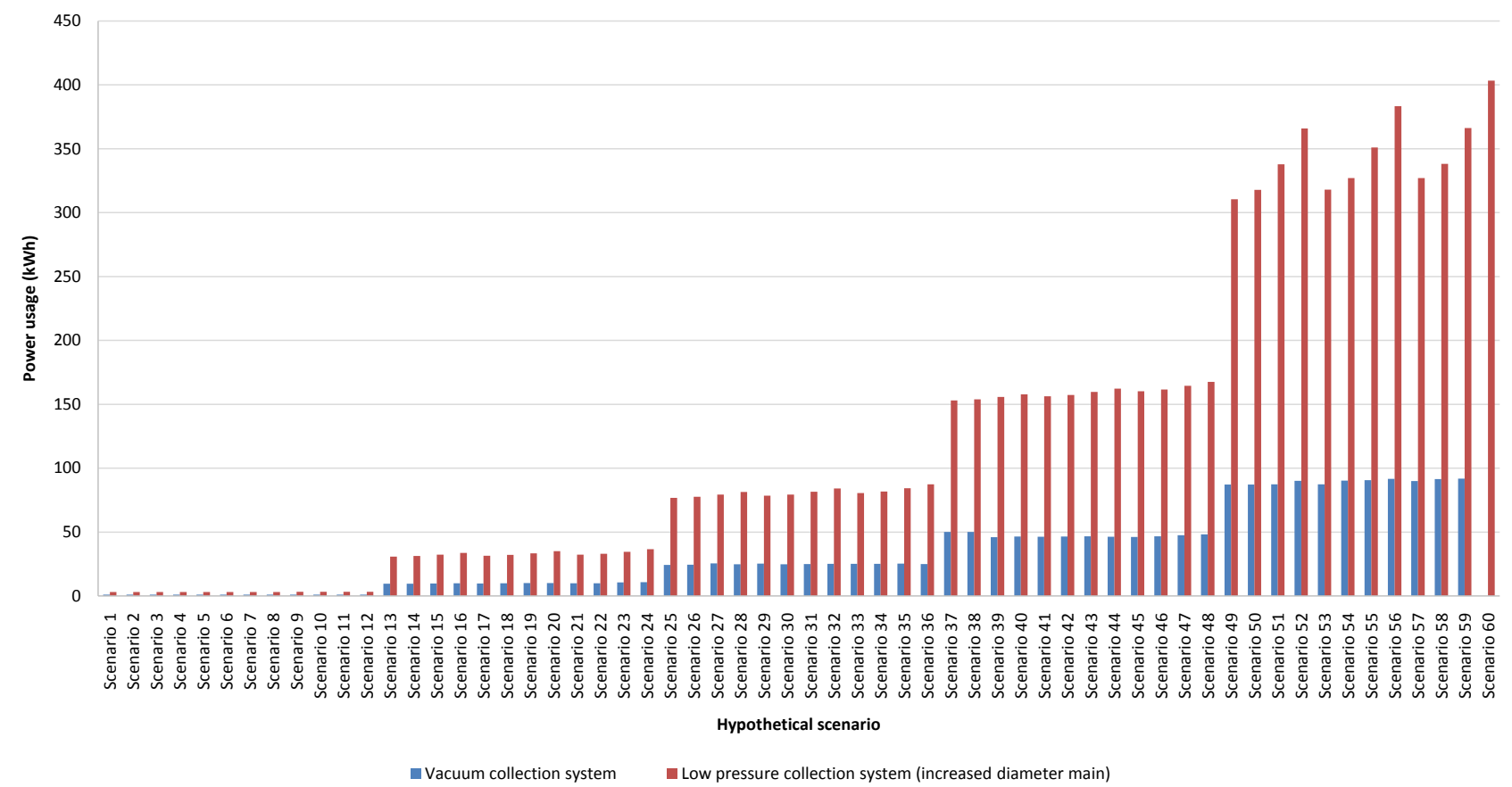

Figure 3. Hypothetical scenario test results for vacuum and low pressure collection systems using different diameter collection mains.

of the vacuum collection system, with all other scenarios seen in Figure 3 requiring a significantly lower energy demand for vacuum than low pressure collection systems.

The energy demand of a low pressure system, as seen in Figure 3, is $3.2-4.2$ 
times that of its equivalent vacuum system in the same scenario, with an average ratio of energy usage for a low pressure to a vacuum collection system of 3.39:1. The major increases in energy usage can be seen to be due to increases in population, causing an increase in flow which therefore increases frictional head loss and pumping duration. Conversely, when using the same diameter main, the energy demand of a low pressure system uses 3.3 - 15.5 times that of its equivalent vacuum system using the same collection system, with an average ratio of energy usage for a low pressure to a vacuum collection system of 4.78:1.

\section{Conclusions}

This study has aimed to compare low pressure and vacuum sewerage systems based on both price and carbon. Hypothetical scenario tests were therefore carried out to obtain operational energy demand and subsequent costs and emissions data for the alternative systems in different situations. This testing method allowed for the creation of accurate data, while assessing several parameters simultaneously. These design parameters were derived from existing literature, with variations in static head, sewer main length and population. The results from these scenario tests have brought about the following conclusions:

1) Increases in the population served by a system, the static head of a system, or the length of the collection main in a system will all result in an increase in the energy demand and subsequent cost and equivalent carbon emissions. Increases in the population served however was found to have the greatest effect, due to the increased population causing an increase in flow, resulting in increased frictional head and pumping times. This highlights the importance of flow reduction for the decarbonization of the water industry.

2) Increasing the diameter of a collection main reduces the energy demand and subsequent cost and equivalent carbon emissions of a system.

3) Depending on the population served a low pressure system may require a greater diameter collection main than a vacuum system in the same scenario. Systems with smaller diameter mains required 1.01 - 4.55 times the amount of energy compared to their larger diameter alternative. This equates to an energy saving of 0.03 - $129.9 \mathrm{kWh}$ per day, resulting in the prevention of $2.8-12,188.89$ $\mathrm{kgCO}_{2} \mathrm{e}$ emissions per year.

4) The equivalent carbon emissions of a collection system is directly affected by the sustainability of the energy source, with a difference of $0.0354 \mathrm{kgCO}_{2} \mathrm{e}$ per $\mathrm{kWh}$ between UK and Ireland energy sources equating to a difference of up to $18.88 \mathrm{kgCO}_{2} \mathrm{e}$ per day for the scenarios tested. Therefore, the adoption of sustainable energy sources should be prioritized for the decarbonization of the water industry to be achieved.

5) The energy demand of a low pressure system is 3.3 - 15.5 times greater than that of its equivalent vacuum system in the same scenario using the same diameter collection main. Conversely, when using a larger diameter main for the low pressure system the energy demand is $3.2-4.2$ times that of its equivalent 
vacuum system in the same scenario. The use of the increased diameter pipes may therefore be necessary for low pressure systems to minimize the whole life cost of the system.

6) The average energy demand of a low pressure system is 3.4 times greater than that of a vacuum system.

\section{Recommendations for Further Research}

This research has highlighted knowledge gaps that require further research. These include:

1) To allow for a comparison between the two collection systems this study carried out hypothetical scenario testing based on scenarios in which both systems could operate. As discussed above, these scenarios covered the operational range of the vacuum system, with no possible solution being found for the final scenario. This study therefore has not assessed the energy demands of a low pressure system in further scenarios beyond the capabilities of the vacuum system. Further research is required to provide designers with the operational energy demands of this system for the remainder of its operational range.

2) The energy requirements of the alternative collection systems septic tank effluent gravity and septic tank effluent pressure systems have not been assessed in this study. Further research is required to provide designers with the operational energy demands of these systems.

3) Analysis of the optimum diameter collection main should be carried out to minimize pumping and subsequent whole-life costs of a low pressure system.

4) This study has provided data regarding the operational carbon emissions due to energy usage. Further research is required to assess the carbon emissions from construction, maintenance and demolition of alternative collection systems to assess the whole life footprint of the systems.

\section{Conflicts of Interest}

The authors declare no conflicts of interest regarding the publication of this paper.

\section{References}

[1] World Commission on Environment and Development (1987) Our Common Future. Oxford University Press, Suffolk.

[2] Reckien, D., Creutzig F., Fernandez, B., Lwasa, S., Tovar-Restrepo, M., Mcevoy, D., et al. (2017) Climate Change, Equity and the Sustainable Development Goals: An Urban Perspective. Environment and Urbanization, 29, 159-182. https://doi.org/10.1177/0956247816677778

[3] Læsøe, J., Schnack, K. and Breiting, S. (2009) Climate Change and Sustainable Development: The Response from Education-Cross-National Report. International Alliance of Leading Educational Institutes, Copenhagen.

[4] Zolghadr-Asli, B., Bozorg-Haddad, O., et al. (2017) Strategic Importance and Safety of Water Resources. Journal of Irrigation and Drainage Engineering, 143, 1-6. 
https://doi.org/10.1061/(ASCE)IR.1943-4774.0001181

[5] NI Water (2018) Annual Information Return 2018 for Public Domain. https://www.niwater.com/sitefiles/resources/pdf/reports/air/air18_public_domain_r esized.pdf

[6] Ashley, R., Blackwood, D., Butler, D., Davies, J., Jowitt, P. and Smith, H. (2003) Sustainable Decision Making for the UK Water Industry. Proceedings of the Institution of Civil Engineers. Engineering Sustainability, 156, 41-49. https://doi.org/10.1680/ensu.156.1.41.37058

[7] Capodaglio, A.G. and Olsson, A. (2020) Energy Issues in Sustainable Urban Wastewater Management: Use, Demand Reduction and Recovery in the Urban Water Cycle. Sustainability, 12, 266. https://doi.org/10.3390/su12010266

[8] Lu, L., Guest, J.S., Peters, C.A., Zhu, X., Rau, G.H. and Ren, Z.J. (2018) Wastewater Treatment for Carbon Capture and Utilization. Nature Sustainability, 1, 750-758. https://doi.org/10.1038/s41893-018-0187-9

[9] NI Water (2019) Annual Report \& Accounts 2018/19. https://www.niwater.com/publications

[10] Roux, P., Mur, I., Risch, E. and Boutin, C. (2011) Urban Planning of Sewer Infrastructure: Impact of Population Density and Land Topography on Environmental Performances of Wastewater Treatment Systems. The LCM 2011 International Conference on Life Cycle Management, Berlin, 28-31 August 2011.

[11] McDermott, R., Solan, B., McCord, S. and Littlewood, K. (2019) Irish Water and Scottish Water: A Comparison. Journal of Water Resource and Protection, 11, 1064-1089. https://doi.org/10.4236/jwarp.2019.118063

[12] Hensley, W.T. (2012) Wastewater Collection Systems Comparison. 2012 Wastewater Purification and Reuse International Conference, Heraklion, 28-30 March 2012.

[13] Tebbutt, T.H.Y. (2013) Basic Water and Wastewater Treatment. 2nd Edition, Butterwell \& Co., London.

[14] Zhao, W., Beach, T.H. and Rezgui, Y. (2016) Optimization of Potable Water Distribution and Wastewater Collection Networks: A Schematic Review and Future Research Directions. IEEE Transactions on Systems, Man and Cybernetics, 46, 659-681. https://doi.org/10.1109/TSMC.2015.2461188

[15] Elawwad, A., Ragab, M. and Abdel-Halim, H. (2014) Vacuum Sewerage System in Developing Regions and the Impact on Environmental Management. Proceedings of the 4th International Conference on Environmental Pollution and Remediation, Prague, 11-13 August 2014.

[16] Gikas, P., Ranieri, E., Sougioultzis, D., Farazaki, M. and Tchobanoglous, G. (2017) Alternative Collection Systems for Decentralized Wastewater Management: An Overview and Case Study of the Vacuum Collection System in Eretria Town, Greece. Water Practice and Technology, 12, 604-618. https://doi.org/10.2166/wpt.2017.050

[17] Islam, M.S. (2016) Comparative Evaluation of Vacuum Sewer and Gravity Sewer Systems. International Journal of System Assurance Engineering and Management, 8, 37-53. https://doi.org/10.1007/s13198-016-0518-z

[18] Terryn, I.C.C., Lazar, I., Nedeff, V. and Lazar, G. (2014) Conventional vs. Vacuum Sewerage System in Rural Areas and Economic and Environmental Approach. Environmental Engineering and Management Journal, 13, 1847-1859. https://doi.org/10.30638/eemj.2014.204

[19] Capodagilio, A.G. (2017) Integrated, Decentralized Wastewater Management for Resource Recovery in Rural and Peri-Urban Areas. Resources, 6, 22. 
https://doi.org/10.3390/resources6020022

[20] The Water Research Foundation (2010) Performance \& Cost of Decentralized Unit Process.

https://www.waterrf.org/research/projects/performance-and-costs-decentralized-un it-processes

[21] United States Environmental Protection Agency (2002) Wastewater Technology Fact Sheet: Sewers, Pressure.

https://www.epa.gov/sites/production/files/2015-06/documents/presewer.pdf

[22] Miszta-Kruk, K. (2016) Reliability and Failure Rate Analysis of Pressure, Vacuum and Gravity Sewer Systems Based on Operating Data. Engineering Failure Analysis, 61, 37-45. https://doi.org/10.1016/j.engfailanal.2015.07.034

[23] Molatore, T.L. (2017) Operational Cost of Two Pressure Sewer Technologies: Effluent (STEP) Sewers and Grinder Sewers.

https://www.wateronline.com/doc/operational-costs-of-two-pressure-sewer-technol ogies-effluent-step-sewers-0001

[24] Burden, D.G., Anderson, D.L. and Zoeller, P. (2003) Septic vs. Sewer: A Cost Comparison for Communities in Sarasota County, Florida. Proceedings of Water Environment Federation, 2004, 319-343. https://doi.org/10.2175/193864703784640875

[25] Engin, G.O. and Demir, I. (2006) Cost Analysis of Alternative Methods for Wastewater Handling in Small Communities. Journal of Environmental Management, 79, 357-363. https://doi.org/10.1016/j.jenvman.2005.07.011

[26] Kaner, C.J.D. (2013) An Introduction to Scenario Testing. Florida Institute of Technology, Melbourne, 1-13.

[27] Yu, P.L.H., Li, W.K. and Ng, F.C. (2014) Formulating Hypothetical Scenarios in Correlation Stress Testing via a Bayesian Framework. The North American Journal of Economics and Finance, 27, 17-33. https://doi.org/10.1016/j.najef.2013.10.002

[28] Airvac (2008) Design Manual. https://www.scribd.com/document/252048951/AIRVAC-Design-Manual-2008

[29] British Water (2013) Flows and Loads. 4th Edition, British Water, London.

[30] Irish Water (2018) Code of Practice for Wastewater Infrastructure. https://www.water.ie/connections/Wastewater-Code-of-Practice.pdf

[31] Redivac (2020) Vacuum Sewers: Vacuum Pipework. https://www.iseki-vacuum.com/how-it-works/vacuum-sewers

[32] Edgeplast Ireland Ltd. (2020) PE Pipe Chart. https://egeplast.ie/pipe/pe-pipe-chart

[33] Environment One (2020) Low Pressure Sewer Systems Using Environment One Grinder Pumps. http://eone.com/images/files/lpsdesign.pdf

[34] Busch (2020) MINK MM-For Rough Vacuum Industrial Applications. https://www.buschvacuum.com/uk/en/products/mink/mink-mm

[35] Environment One (2020) D-Series DH071 \& DR071 Grinder Pump Station. https://eone.com/sewer-systems/products/grinder-pumps/d/dh071

[36] Department for Business, Energy \& Industrial Strategy (2019) Greenhouse Gas Reporting: Conversion Factors 2019. https://www.gov.uk/government/publications/greenhouse-gas-reporting-conversio n-factors-2019

[37] Committee on Climate Change (2019) Net Zero-The UK's Contribution to Stopping Global Warming. Report. London. 